\title{
UNCOORDINATED FAUNAL STASIS IN JURASSIC MARINE BENTHIC INVERTEBRATE PALEOCOMMUNITIES, WESTERN INTERIOR, U.S.A.
}

\author{
TANG*, Carol M., and BOTTJER, David J., Department of Earth Sciences, \\ University of Southern California, Los Angeles, CA 90089-0740, U.S.A.
}

A quantitative analysis of previously-published and newly-collected taxonomic and paleoecological data indicates that strong and extended intervals of stasis existed in marine invertebrate paleocommunities of the Jurassic North American epicontinental seaway. This study represents the first example of faunal stasis in the Mesozoic and unlike other documented cases of faunal stasis, the stability recognized here extended for greater intervals of time and was not coordinated among species. This suggests that these paleocommunities were not tightly integrated and that this pattern was a result of stasis within individual lineages and not due to community-level processes.

The low-diversity, bivalve-dominated, marine invertebrate assemblages we studied were deposited in a mixed carbonate-siliciclastic system of a shallow, restricted, epicontinental seaway which covered the western interior (Montana, Wyoming, South Dakota, Utah) during the Jurassic. Marine deposition in the seaway can be divided into 6 major cycles of deposition, each representing about 2-6 m.y. and separated by major regional unconformities.

Results indicate that species, genera, and distinct paleocommunities persisted through many cycles of deposition representing many marine transgressions and regressions. In each depositional unit, we find that $16-92 \%$ of species (average $53 \%$ ) are carryovers (continuing into the next cycle of deposition) while $32-100 \%$ (average $64 \%$ ) are holdovers (derived from previous cycle). These values are much higher than those reported in other faunal stasis studies. In addition to the observed stasis in generic/species composition, distinct paleocommunity associations also persisted through cycles of deposition and changes in sea level.

This stability, however, does not appear to have been a result of "ecological locking," but rather was a result of many long-lived species associated with a small proportion of more short-lived taxa. The evidence for loosely integrated paleocommunities comes from: (1) the incorporation of rare, exotic taxa (epibole analogues) into existing faunal associations; (2) a bimodal distribution of species durations with most either extremely short-lived or long-lived; and (3) turnover among some species within paleocommunities while others persisted.

This pattern of faunal stasis may be due to the abundance in these assemblages of generalist taxa, which have been hypothesized to have low extinction rates. These paleocommunities are also heavily dominated by bivalves, which have very long average species durations. The lack of coordinated turnover among the faunas argues against the presence of intrinsic ecological "locking" mechanisms and suggests that the Jurassic faunal stasis may be due to environmental tracking, reduced numbers of invading taxa, and inherently low extinction rates. 